\title{
UTILIZAÇÃO DE DIFERENTES SUBSTRATOS NA GERMINAÇÃO DO GIRASSOL
}

\author{
Fábio Janoni Carvalho ${ }^{1}$, Denise Garcia de Santana ${ }^{2}$ \\ ${ }^{1}$ Msc. Eng. Agr., da Universidade Federal de Uberlândia (fabiojanoni@ufu.br), \\ Uberlândia-Minas Gerais \\ ${ }^{2}$ Prof. Dra. em Agronomia da Universidade Federal de Uberlândia, Uberlândia-Minas \\ Gerais \\ Recebido em: 16/11/2015 - Aprovado em: 10/12/2015 - Publicado em: 21/12/2015 \\ DOI: http://dx.doi.org/10.18677/Agrarian_Academy_021
}

\begin{abstract}
RESUMO
O cultivo do girassol possui características favoráveis no Brasil, graças a sua adaptabilidade nas várias regiões, resistência à seca, ao frio e ao calor e baixo custo de produção. O experimento foi realizado no laboratório de sementes da Universidade Federal de Uberlândia. Foram utilizadas sementes de girassol do híbrido H.251. Anteriormente ao teste foi executado um pré-teste para eliminar os piores tratamentos devido a poucas sementes do lote avaliado. Para o teste realizou-se um experimento constando de quatro tratamentos, sendo o tratamento 1 a testemunha, realizada da forma convencional, o tratamento 2 a adição de $10 \mathrm{~mL}$ de areia no papel semeado, o tratamento 3 a adição de $10 \mathrm{~mL}$ de areia no rolo de germinação no papel abaixo daquele semeado e o tratamento 4 a adição de $5 \mathrm{~mL}$ de areia no rolo de germinação no papel abaixo daquele semeado. O teste constituiu de um esquema fatorial tratamento $x$ lote em DIC, conduzido na BOD a $25^{\circ} \mathrm{C}$, com avaliação feita cinco dias após a montagem do experimento. Há necessidade de alteração do teste de germinação do girassol recomendado pela RAS. O problema da germinação esta ligado com a falta de aeração do rolo, em que a adição de substrato contorna o problema. A adição de $5 \mathrm{~mL}$ de areia no rolo de germinação no papel abaixo daquele semeado permite maiores germinações e a leitura do teste é facilitada, por não ocorrer contato entre a semente e o substrato.
\end{abstract}

PALAVRAS-CHAVE: aeração do rolo, Germinação em substratos, Helianthus annuus

\section{USE OF DIFFERENT SUBSTRATES IN SUNFLOWER GERMINATION}

\begin{abstract}
The cultivation of sunflower has favorable characteristics in Brazil, due to its adaptability in various regions, its resistance to drought, cold and heat and low production cost. The experiment was conducted at seed laboratory of the Federal University of Uberlândia. Sunflower seeds used were from hybrid H.251. Before the test, was performed a pretest to eliminate the worst treatments due to few seeds of the evaluated batch. For the test, the experiment consist in four treatments, where treatment 1 was control, performed in the conventional manner, treatment the addition of $10 \mathrm{~mL}$ of sand in the seeded paper, treatment 3 the addition of $10 \mathrm{~mL}$ of sand in germination roll paper below that sown and treatment 4 the addition of $5 \mathrm{~mL}$
\end{abstract}


of the germination sand roll on the paper below that sown. The test consisted of a factorial treatment $x$ batch in a completely randomized design, conducted in BOD at $25^{\circ} \mathrm{C}$, with evaluation five days after assembly of experiment. There is a need to change sunflower germination test recommended by RAS. The problem of germination is connected with the lack of aeration in roller, wherein the addition of substrate circumvents the problem. The addition of $5 \mathrm{~mL}$ of the germination sand roll on the paper beneath that allows higher germination and test reading is facilitated because no contact occurs between the seed and the substrate.

KEYWORDS: Germination substrates, Helianthus annuus, roller aeration.

\section{INTRODUÇÃO}

O cultivo do girassol (Helianthus annuus L.) possui características favoráveis no Brasil, graças a adaptabilidade nas várias regiões, resistência à seca, ao frio e ao calor e baixo custo de produção, permitindo que esta seja uma alternativa para plantio em época de safrinha (BACAXIXI et al. 2011). Há diversas formas para o aproveitamento, destacando-se o uso medicinal, ornamental, em adubação verde, em rotação de culturas, na apicultura, na alimentação de animais, na produção de óleo, para alimentação humana e na produção de biodiesel (SILVA et al., 2011).

A espécie está inserida entre as plantas com maior potencial para a produção de biocombustível. Também constitui em uma importante opção para o produtor agrícola em sistemas que envolvem rotação ou sucessão de culturas (MENEZES et al., 2015). A propagação do girassol é essencialmente seminífera, sendo primordial a utilização de sementes com alta qualidade. Assim, é necessária a reunião de todos os atributos da semente, como o genético, o físico, o fisiológico e o sanitário, que contribuem para a formação de plantas vigorosas (NOBRE et al., 2013). A semente é o veículo em que estão contidos as inovações e os avanços tecnológicos visando à agregação de valor ao produto a ser transferido para o agricultor, representando altos ganhos econômicos ao setor agrícola (BRASIL, 2011).

A germinação de sementes ocorre quando as condições para o crescimento são favoráveis e estas não apresentam algum tipo de dormência. A busca de conhecimentos sobre as condições ideais de germinação para o desenvolvimento inicial das plantas desempenha papel fundamental dentro da pesquisa científica e fornece informações valiosas sobre a propagação das espécies (SOUZA et al., 2013). É necessário considerar que a semente precisa atingir todas as fases da germinação, desde a embebição até a protrusão da radícula. Há técnicas de condicionamento osmótico que auxiliam na embebição controlada das sementes, antes destas serem levadas para o campo (RABBANI et al., 2013).

As sementes de girassol estão sujeitas às variações edafoclimáticas, em especial a disponibilidade hídrica do solo, na ocasião da semeadura. Sementes de diversas espécies, quando submetidas à restrição hídrica no solo, reduzem a germinação e desenvolvimento em razão da interferência no processo de embebição e de alongamento celular (BACKES et al., 2008). Para o girassol a situação se agrava, pois por possuírem mais de $45 \%$ de reservas oleaginosas, esse atraso é ainda mais prejudicial, pois favorece a infecção por patógenos, além de aumentar as chances de deterioração em função da peroxidação de lipídios (SANTOS et al., 2013).

O conhecimento prévio da germinação de um lote é primordial para o produtor, para que este pague o verdadeiro valor de uma semente além de saber a quantidade exata de sementes que deverão ser semeadas. $O$ teste padrão proposto 
pela Regra de Análise de Sementes (BRASIL, 2009) subestima os lotes, por problemas devido a falta de aeração do rolo. A adição de algum tipo de substrato para contornar o problema é proposto por alguns laboratórios de rotina. $\mathrm{O}$ objetivo do trabalho foi avaliar a influência de diferentes substratos na germinação do girassol adicionados ao papel do teste, assim como as suas diferentes quantidades e forma de distribuição.

\section{MATERIAL E MÉTODOS}

O experimento foi realizado no laboratório de sementes (LASEM \& LASEF) da Universidade Federal de Uberlândia. Foram utilizadas sementes de girassol do híbrido H.251 com 100\% de germinação em 15/12/2011. Anteriormente ao teste foi executado um pré-teste para eliminar os piores tratamentos devido a poucas sementes do lote avaliado. Para isto, realizou-se dois rolos de germinação para observação com 10 tratamentos diferentes (Quadro 1). Os substratos utilizados foram a areia e a vermiculita, variando-se 5 a $50 \mathrm{~mL}$ a quantidade colocada no papel. A distribuição foi realizada com o peneiramento do substrato no papel de contato com a semente, pulverizada sobre o papel ou apenas ao redor da semente. Também foi estudada a repetição com vermiculita abaixo do papel semeado. Os rolos foram acondicionados em estufa do tipo BOD a $25^{\circ} \mathrm{C}$, e a avaliação foi feita cinco dias após a montagem do experimento.

QUADRO 1. Tratamentos utilizados no pré-teste com o tipo de substrato, a quantidade e a sua forma de distribuição.

\begin{tabular}{cccc}
\hline TRATAMENTO & SUBSTRATO & QUANTIDADE & DISTRIBUIÇÃO \\
\hline $\mathbf{1}$ & Areia & $5 \mathrm{~mL}$ & Ao redor da semente \\
$\mathbf{2}$ & Areia & $10 \mathrm{~mL}$ & Ao redor da semente \\
$\mathbf{3}$ & Vermiculita & $5 \mathrm{~mL}$ & Ao redor da semente \\
$\mathbf{4}$ & Vermiculita & $10 \mathrm{~mL}$ & Ao redor da semente \\
$\mathbf{5}$ & Vermiculita & $25 \mathrm{~mL}$ & Ao redor da semente \\
$\mathbf{6}$ & Areia & $10 \mathrm{~mL}$ & Sobre o papel semeado \\
$\mathbf{7}$ & Vermiculita & $10 \mathrm{~mL}$ & Sobre o papel semeado \\
$\mathbf{8}$ & Vermiculita & $25 \mathrm{~mL}$ & Sobre o papel semeado \\
$\mathbf{9}$ & Vermiculita & $50 \mathrm{~mL}$ & Sobre o papel semeado \\
$\mathbf{1 0}$ & Vermiculita & $25 \mathrm{~mL}$ & No papel abaixo daquele \\
& & & semeado \\
\hline
\end{tabular}

Todos os tratamentos obtiveram percentuais de germinação próximos de $100 \%$. Assim, objetivando a melhor metodologia para o teste de germinação, levouse em consideração o tratamento que permite melhor facilidade na execução e leitura, além de menores quantidades de substrato.

Para o teste realizou-se um experimento constando de quatro tratamentos, sendo o tratamento 1 a testemunha, realizada da forma convencional recomendada pela RAS (BRASIL, 2009), o tratamento 2 a adição de $10 \mathrm{~mL}$ de areia no papel semeado, o tratamento 3 a adição de $10 \mathrm{~mL}$ de areia no rolo de germinação no papel abaixo daquele semeado e o tratamento 4 a adição de $5 \mathrm{~mL}$ de areia no rolo de germinação no papel abaixo daquele semeado. Escolheu-se os tratamentos com areia ao invés de vermiculita, pois a areia é um produto mais barato e mais fácil de ser encontrado em um laboratório, além de que a vermiculita varia muito quanto a granulometria, portanto de difícil padronização. 
Como havia apenas lotes de germinação alta no laboratório, as sementes foram mortas para mistura de lotes e a criação de três lotes com porcentagens de germinação diferentes. Entretanto mesmo levando as sementes para estufa por duas horas a $70^{\circ} \mathrm{C}$, as mesmas não morreram, sendo então testados apenas três lotes de alta qualidade.

$O$ teste constituiu de um esquema fatorial tratamento $x$ lote em DIC, conduzido na $\mathrm{BOD}$ a $25^{\circ} \mathrm{C}$, com avaliação feita cinco dias após a montagem do experimento. $O$ experimento foi montado no dia cinco de agosto de 2013. Realizouse quatro repetições de cada lote dentro de cada tratamento. Cada repetição possuía 25 sementes. Foi contabilizada a germinação e foi feito também a análise visual das plântulas formadas. A porcentagem de germinação foi submetida à análise de variância após o atendimento das pressuposições do modelo pelos testes de Shapiro-Wilk, para normalidade dos resíduos, e de Levene, para homogeneidade das variâncias, ambos a $5 \%$ de significância. As médias foram comparadas pelo teste de Tukey, a $5 \%$ de probabilidade.

\section{RESULTADOS E DISCUSSÃO}

Como esperado, os lotes utilizados não se diferenciaram entre si (Tabela 1) pois todos os lotes possuíam altos índices germinativos. Não ocorreu interação entre tratamento e lote, ou seja, os tratamentos não comportaram-se de forma diferenciada para cada lote. Foi observada diferença significativa para os tratamentos. Relata-se também baixo índice do coeficiente de variação (CV) de $5.99 \%$, mostrando baixa variação entre mesmas repetições no experimento.

TABELA 1. Quadro da análise de variância para os diferentes tratamentos germinativos em lotes de girassol.

\begin{tabular}{ccccc}
\hline Fonte de variação & $\boldsymbol{g l}$ & $\mathbf{Q M}$ & $\mathbf{F}$ & $\boldsymbol{p}$-valor \\
\hline Tratamentos & 3 & 359.444 & 12.686 & $0.000^{\star \star}$ \\
Lotes & 2 & 90.333 & 3.188 & $0.053^{\text {n.s. }}$ \\
Trat. ${ }^{*}$ Lote & 6 & 37.444 & 1.322 & $0.273^{\text {n.s. }}$ \\
Erro & 36 & 28.333 & & \\
\hline CV $(\%)$ & \multicolumn{5}{c}{5.990} \\
\hline
\end{tabular}

Com a aplicação do teste de Tukey (Tabela 2) a 0,05 de significância para os tratamentos, observou-se que todos os tratamentos com substratos diferiram da testemunha, mas não diferiram entre si. Mesmo em lotes de alta germinação, a utilização de algum tratamento com substrato beneficiou a germinação. Se os lotes possuíssem qualidades germinativas diferentes as diferenças entre os tratamentos seria mais abrasiva, pois lotes de menor qualidade possuem desempenho muito menor no tratamento proposto na RAS do que lotes de maior qualidade.

Os melhores substratos devem apresentar, entre outras importantes características, fácil disponibilidade de aquisição e transporte, ausência de patógenos, riqueza em nutrientes essenciais, $\mathrm{pH}$ adequado, boa textura e estrutura (BACAXIXI et al., 2011). O substrato areia apresentou todas estas características e garantiu o bom desenvolvimento da plântula. A utilização de areia para a germinação do girassol mostrou se benéfica também para outros pesquisadores (SILVA et al., 2014). Para sementes de cagaitera, a areia também proporcionou melhores índices germinativos (NIETSCHE et al., 2004). 
TABELA 2. Média da porcentagem de germinação para os tratamentos germinativos aplicados.

\begin{tabular}{cc}
\hline Tratamento & $\mathbf{G}(\%)$ \\
\hline Testemunha & $87 \mathrm{~b}$ \\
Areia $10 \mathrm{~mL}$ no papel & $97 \mathrm{a}$ \\
Areia $10 \mathrm{~mL}$ abaixo papel & $98 \mathrm{a}$ \\
Areia $5 \mathrm{~mL}$ abaixo papel & $99 \mathrm{a}$ \\
\hline Média geral & $95 \%$ \\
Desvio-padrão & 1.42 \\
DMS (5\%) & 1.55 \\
\hline Médias seguidas de letras iguais não se diferenciam entre si pelo teste de \\
Tukey a 0,05 de significância. gl: graus de liberdade; DMS: diferença \\
mínima significativa.
\end{tabular}

Observando-se o vigor das plântulas, também é notória a diferença dos tratamentos perante a testemunha (Figura 1). Plântulas que apresentam maiores comprimentos, massas fresca e seca, numa mesma espécie, indicam maior qualidade fisiológica das sementes que as originaram e, portanto, são consideradas mais vigorosas (DODE et al., 2012). Pensando-se em um teste mais prático, por mais que o tratamento 2, areia no rolo de germinação, apresentou plântulas com raízes mais vigorosas e maior desenvolvimento de raízes secundárias, a leitura foi dificultada pelo contato areia com plântula. Além disso, o crescimento micelial dos fungos é intensificado naquelas plântulas ou sementes contaminadas. Em um rolo com 50 sementes, usual nos laboratórios, a contaminação entre sementes próximas seria mais fácil, o que poderia dificultar na identificação se a infecção é primária ou secundária.

Os tratamentos com areia no rolo de germinação no papel abaixo daquele semeado possuem maior praticidade e facilidade de leitura, pois a semente não fica em contato com a areia. Entretanto durante a montagem do experimento, estes rolos são mais demorados para confecção. Este fato é contorcionado pelo maior vigor das plântulas comparado a testemunha, pois para o girassol o vigor é a principal característica que deve ser analisada para garantia de estande ao produtor (CALDEIRA et al., 2014). 


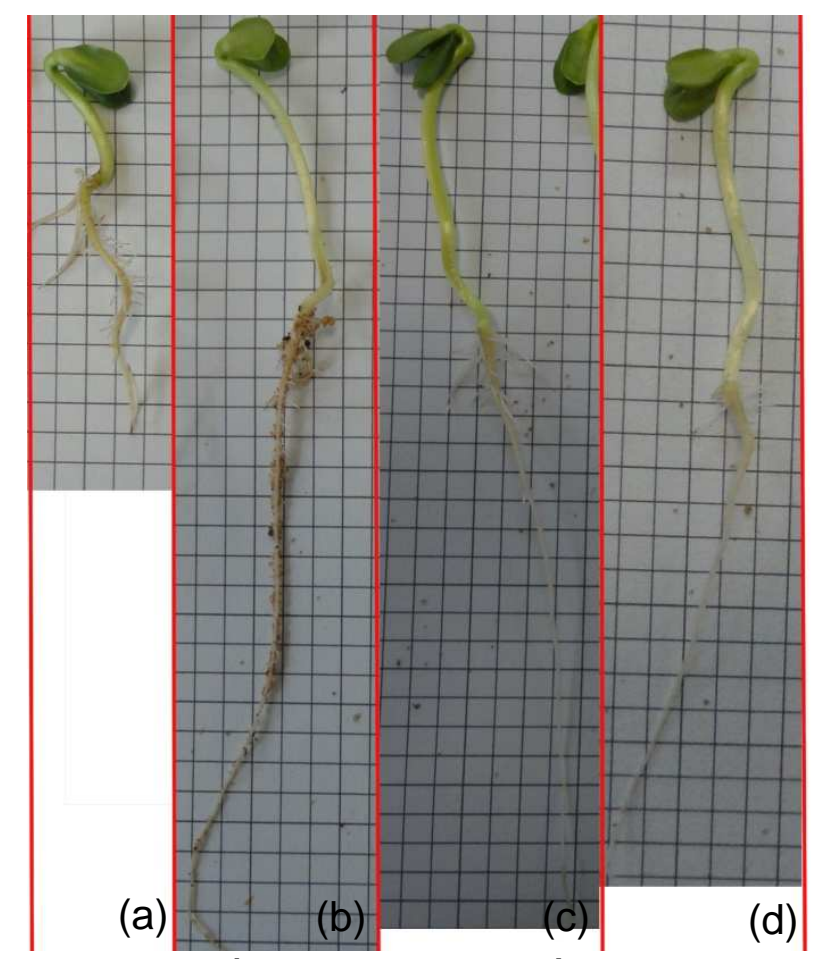

FIGURA 1. Plântulas características de cada tratamento. (a) Testemunha; (b) Areia $10 \mathrm{~mL}$ no papel; (c) Areia $10 \mathrm{~mL}$ abaixo papel; (d) Areia $5 \mathrm{~mL}$ abaixo papel.

\section{CONCLUSÃO}

Há necessidade de alteração do teste de germinação do girassol (Helianthus annuus L.) recomendado pela RAS. O problema da germinação está ligado com a falta de aeração do rolo, em que a adição de substrato contorna o problema. A adição de $5 \mathrm{~mL}$ de areia no rolo de germinação no papel abaixo daquele semeado permite maiores germinações e a leitura do teste é facilitada, por não ocorrer contato entre a semente e o substrato.

\section{REFERÊNCIAS}

BACAXIXI, P.; RODRIGUES, L.R.; BUENO, C.E.M.S.; RICARDO, H. A.; EPIPHANIO, P.D.; SILVA, D.P.; BARROS, B.M.C.; SILVA, T.F. Teste de germinação de girassol (Helianthus annuus L.) Revista Científica Eletrônica de Agronomia, n. 20, 2011. Disponível em: <http://faef.revista.inf.br/imagens_arquivos/arquivos _destaque/s7YDzJcHEZBp5ip_2013-5-17-15-21-50.pdf>

BACKES, R.L.; SOUZA, A.M.; JUNIOR, A.A.B.; GALLOTTI, G.J.M; BAVARESCO, A. Desempenho de cultivares de girassol em duas épocas de plantio de safrinha no planalto norte catarinense. Scientia Agricola, v.9, n.1, p.41-48, 2008. Disponível em: <http://dx.doi.org/10.5380/rsa.v9i1.10131> doi: < 10.5380/rsa.v9i1.10131>

BRASIL, Ministério da Agricultura e Reforma Agrária. Regras para análise de sementes. Brasília, Secretaria Nacional de Defesa Agropecuária, 2009. 398p. 
BRASIL. Ministério da Agricultura Pecuária e Abastecimento. Guia de inspeção de campos para produção de sementes. Secretaria de Defesa Agropecuária. 3. ed. revisada e atualizada - Brasília: Mapa/ ACS, 2011. 41 p.

CALDEIRA, C.M.; CARVALHO, M.L.M.; OLIVEIRA, J.A.; COELHO, S.V.B.; KATAOKA, V.Y. Vigor de sementes de girassol pela análise computadorizada de plântulas. Científica, Jaboticabal, v.42, n.4, p.346-353, 2014. Disponível em: < http://dx.doi.org/10.15361/1984-5529.2014v42n4p346-353> doi: <10.15361/19845529.2014v42n4p346-353>

DODE, J.S.; MENEGHELLO, E.; MORAES, D.M.; PESKE, S.T. Teste de respiração para avaliar a qualidade fisiológica de sementes de girassol. Revista Brasileira de Sementes, v.34, n.4, p.686-691, 2012. Disponível em: < http://dx.doi.org/10.1590/S0101-31222012000400021> doi: <10.1590/S010131222012000400021

MENEZES, A.S.; RIBEIRO, A.A.; TAVARES, M.K.N.; SANTOS, C.K.G.; ARAGÃO, M.F.; MOREIRA, F.J.C. Salinidade na germinação e crescimento inicial de girassol (Helliantus annus L.) submetido a estresse salino. Revista Agrogeoambiental, Pouso Alegre, v.7, n.2, p.23-32, 2015.

NIETSCHE, S.; GONÇALVES, V.D.; PEREIRA, M.C.P.; SANTOS, F.A.; ABREU, S.C.; MOTA, W.F. Tamanho da semente e substratos na germinação e crescimento inicial de mudas de cagaiteira. Ciência Agrotecnologia, Lavras, v.28, n.6, p.13211325, 2004. Disponível em: < http://dx.doi.org/10.1590/S1413-70542004000600014 $>$ doi: <10.1590/S1413-70542004000600014>

NOBRE, D.A.C.; JUNIOR, D.S.B.; COSTA, C.A.; RESENDE, J.C.F.; MARTINS, M. Avaliação da qualidade fisiológica de sementes em genótipos de girassol. Revista de Ciências Agrárias, v.56, n.3, p.196-201, 2013. Disponível em: < http://dx.doi.org/10.4322/rca.2013.0297623> doi: <10.4322/rca.2013.0297623>

RABBANI, A.R.C.; NUNES, F.B.S.; CARVALHO, S.V.A.; FERREIRA, R.A.; MANN, R.S. Condicionamento osmótico em sementes de girassol (Helianthus annuus L.). Revista Científica UDO Agrícola, v.13, n.1, p.50-55, 2013. Disponível em: <http://udoagricola.orgfree.com/V13N1UDOAg/V13N1Rabbani50.pdf> Acesso em 10 de outubro de 2015.

SANTOS, C.A.C; PEIXOTO, C.P.; VIEIRA, E.L; CARVALHO, E.V.; PEIXOTO, V.A.B. Stimulate ${ }^{\circledR}$ na germinação de sementes, emergência e vigor de plântulas de girassol. Bioscience Journal, Uberlândia, v.29, n.2, p.605-616, 2013. Disponível em: < http://www.seer.ufu.br/index.php/biosciencejournal/article/view/14091/12502>

SILVA, A.R.A.; BEZERRA, F.M.L.; SOUSA, C.C.M.; PEREIRA FILHO, J.V.;FREITAS, C.A.S. Desempenho de cultivares de girassol sob diferentes lâminas de irrigação no Vale do Curu, CE. Revista Ciência Agronômica, v.42, n.1, p.57-64, 2011. Disponível em: <http://dx.doi.org/10.1590/S1806-66902011000100008 > doi: $<10.1590 /$ S1806-66902011000100008> 
SILVA, V.F.; BRITO, K.S.A.; NASCIMENTO, E.C.S.; ANDRADE, L.O.; FERREIRA, A.C. Efeito de diferentes substratos na germinação de genótipos de girassol. Revista Verde de Agroecologia e Desenvolvimento Sustentável, v.9, n.4, p.1620, 2014.

SOUZA P.S.; RIGO, M.M.; CERQUEIRA, A.A.; FERREIRA, A.C.; MARQUES, M.R.; PEREZ, D.V. Efeito de diferentes dosagens de $\mathrm{Fe}^{3+}$ na germinação do girassol. Revista Internacional de Ciências, v.3, n.2, p.73-82, 2013. Disponível em: <http://dx.doi.org/10.12957/ric.2013.7623> doi: <10.12957/ric.2013.7623> 